\title{
EFFECTS OF GRAIN AND PRECIPITATE SIZE VARIATION ON CREEP-FATIGUE BEHAVIOUR OF UDIMET 720LI IN BOTH AIR AND VACUUM
}

\author{
${ }^{1}$ N.J. Hide, ${ }^{2}$ M.B. Henderson and ${ }^{1}$ P.A.S. Reed \\ ${ }^{1}$ Materials Research Group, School of Engineering Sciences, University of Southampton, Southampton, SO17 1BJ, U.K. \\ ${ }^{2}$ Mechanical Sciences Sector, DERA Farnborough, Farnborough, GU14 OLS, U.K.
}

\begin{abstract}
The high temperature fatigue characteristics of $\mathrm{U} 720 \mathrm{Li}$ have been investigated over the temperature range $650^{\circ} \mathrm{C}$ to $725^{\circ} \mathrm{C}$ under imposed dwell times (at maximum load) of 1 and 20 seconds in vacuum and air conditions. The effect of varying grain size and coherent precipitate size under these conditions has been assessed.

Testing in air resulted in oxidation dominated intergranular crack growth at all temperatures and dwell times with the slope (m-values) of the crack growth rate curves remaining constant. Increased crack growth rates are seen at the higher temperatures and at longer dwells, although no effect of dwell was observed at $650^{\circ} \mathrm{C}$ in the as-received fine grained variant. In vacuum crack growth rates were much lower than in air and a purely cyclic dependent regime was evident at $650^{\circ} \mathrm{C}$. As temperature and dwell time at maximum load was increased, $\mathrm{m}$ values increased and were accompanied by a change in crack growth mechanism from transgranular to intergranular cracking. This indicated that true, time-dependent, creepfatigue processes were occurring.
\end{abstract}

The large grain variant of the U720Li showed little advantage in crack growth rates within the cyclic dependent and creepfatigue regime, but did show a significant increase in resistance to crack growth in the time dependent (oxidationfatigue) regime. The effect of the large precipitate variant was to give similar or worse crack growth resistance than the baseline U720 Li at temperatures up to $725^{\circ} \mathrm{C}$ (1 second dwell) but improved crack growth resistance when oxidation processes predominated at $725^{\circ} \mathrm{C}$ in air with an imposed 20 second dwell.
Introduction

Engine operating temperatures are being pushed ever higher with target temperatures for nickel-base disc materials such as U720Li now approaching $725^{\circ} \mathrm{C}$ to improve aero-engine efficiency. Service conditions for these alloys are severe due to operating temperature, oxidation and the fluctuating loads imposed during engine start-up and shut-down cycles. These conditions pose problems in terms of high temperature fatigue, oxidation assisted fatigue and (when sub-surface defects occur which grow in an effective vacuum) creep-fatigue. Optimisation of turbine materials so that operating temperatures can be maximised thus requires a fundamental understanding of the mechanisms involved in high temperature fatigue and oxidation/creep-fatigue as well as an assessment of the optimised microstructure.

Nickel-base superalloys largely comprise an austenitic f.c.c. matrix ( $\gamma$ phase) and coherent nickel rich $\gamma^{\prime}$ precipitates, from which the material derives most of its strength and creeprupture properties. As such the characteristics of the $\gamma$ grains and $\gamma^{\prime}$ precipitates can significantly alter the fatigue and oxidation/creep-fatigue properties of the material. At elevated temperatures material properties such as $\mathrm{E}$ and $\sigma_{\mathrm{y}}$ decrease and creep deformation and environmental effects become important (1). Slip character also changes as cross-slip and climb processes become easier. Cycle dependent behaviour is observed at intermediate temperatures, where crack growth rates are independent of frequency, but may be increased due to decreases in $E$ and $\sigma_{y}$ increasing the $\triangle C T O D$. Such crack growth is generally characterised by a transgranular crack propagation mechanism. At higher temperatures frequency effects start to become apparent, with higher crack growth rates observed at lower frequencies (time-dependent behaviour). The transition from transgranular to intergranular crack growth is widely acknowledged to indicate the onset of time dependent behaviour $(2,3,4)$. This may be caused by environmental effects (5) such as grain boundary embrittlement or from true creep effects, which are usually observed under vacuum $(2,6)$ and are facilitated by triple point cracking or grain boundary sliding and consequent cavity formation. The point at which intergranular crack growth occurs (under any environment) may be linked to the amount of stress experienced by the grain boundary and the integrity of the grain boundary in relation to the ease with which cracks can propagate transgranularly. The amount of stress present at a grain boundary can be associated with the slip character of the material, which in turn is linked to the coherent $\gamma^{\prime}$ characteristics $(2,7,8)$. Fine $\gamma^{\prime}$ precipitates have been associated with slip of a highly planar and heterogeneous nature (1), and whilst this may be beneficial for increasing resistance to crack growth at room temperatures (through increased $\sigma_{y}$ ) the intersection of intense planar slip bands at
Superalloys 2000

Edited by T.M. Pollock, R.D. Kissinger, R.R. Bowman,

K.A. Green, M. McLean, S. Olson, and J.J. Schirra

TMS (The Minerals, Metals \& Materials Society), 2000 
grain boundaries may occur. At high temperatures, a high build-up of stress concentration through this mechanism can cause crack propagation through wedge cracking or grain boundary sliding. Increasing the coherent $\gamma^{\prime}$ size has been cited by a number of authors as decreasing high temperature crack growth rates (in air) through increasing the degree of slip homogeneity within nickel based superalloys and subsequently lowering the stress at grain boundaries giving a resultant longer rupture life $(9,10)$. However, this effect must also be balanced against the decrease in hardness and flow stress that can occur if $\gamma^{\prime}$ are grown into the overaged condition and the concomitant effects on crack growth. In an oxidising environment, the nature of the slip damage can also be important with respect to the diffusion of oxidising species to grain boundaries along intense slip bands. The inference being that a microstructure producing a more intense slip band might well produce an easier path for diffusion of oxidising species $(10,11)$.

Increased grain size has been linked to lower crack growth rates at elevated temperature. Merrick and Floreen (9) when testing $\mathrm{P} / \mathrm{M}$ Astroloy at $650^{\circ} \mathrm{C}$ noted lower fatigue crack growth rates in air when the grain size was increased from ASTM $8(22.5 \mu \mathrm{m})$ to ASTM $5(63.5 \mu \mathrm{m})$. Creep strains in U720Li at $600^{\circ} \mathrm{C}$ showed a decrease when the grain size was increased from $22 \mu \mathrm{m}$ to $420 \mu \mathrm{m}$ which was linked by Torster ef al (12) to a classical grain boundary sliding mechanism. It was however found that the L.C.F. strength decreased with increasing grain size (in-line with variations in yield strength). Grain boundary morphology has also been linked to variation in high temperature crack growth rates with serrated or "wavy" grain boundaries producing lower crack growth rates in air $(9,10)$. This was attributed to an increase in the resistance to grain boundary sliding. It has also been reported that producing wavy grain boundaries increased stress/rupture properties at $>500^{\circ} \mathrm{C}$ in a nickel basc alloy (3). The morphology and distribution of secondary phases (e.g. $\mathrm{M}_{23} \mathrm{C}_{6}$ and primary $\gamma^{\prime}$ ) on grain boundaries may also be expected to affect intergranular crack growth rates. Garimalla et al (7) state that $\mathrm{M}_{23} \mathrm{C}_{6}$ are brittle and deleterious to intergranular crack growth resistance if they occur continuously along grain boundaries, but reduce the propensity for grain boundary sliding and void growth when intermittently decorated along grain boundaries with consequently improved creep/rupture properties. In this context the distribution of intragranular carbides were found to be relatively unimportant. Runkel and Pelloux (13) have also looked at the effects of $\mathrm{M}_{23} \mathrm{C}_{6}$ and primary/grain boundary $\gamma^{\prime}$ distributions on L.C.F. behaviour in Astroloy between $400^{\circ} \mathrm{C}$ and $700^{\circ} \mathrm{C}$ and noted that: Large blocky $\gamma^{\prime}$ gave best resistance to crack growth, a combination of g.b. $\gamma^{\prime}$ and $\mathrm{M}_{23} \mathrm{C}_{6}$ was beneficial, fine g.b. $\gamma^{\prime}$; and a combination of intermittent $\mathrm{M}_{23} \mathrm{C}_{6}+$ some blocky $\mathrm{MC}$ provided the least resistance to crack growth.

Hence we need to assess the effects of grain size/morphology in addition to grain boundary character (including distribution of grain boundary primary $\gamma^{\prime}$ ) and coherent $\gamma^{\prime}$ characteristics to identify high temperature fatigue and creepfatigue resistant microstructures. In this study a fundamental examination of the effects of microstructure on the high temperature fatigue and oxidation/creep fatigue of U720Li has been carried out. The aim is to optimise the alloy's microstructural characteristics for maximum resistance to crack growth under these conditions.

\section{Experimental}

Three material variants were studied, namely a standard asreceived form of powder metallurgy U720Li (base-line material) as well as a large grain (U720LG) and large precipitate variant (U720LP) of U720Li. The U720Li microstructural variants were produced by increasing the solution temperature (to increase grain size) and by slowing the cooling rate from the solution temperature (to increase the coherent precipitate size). The heat treatment routes used for each material are listed in Table I.

\begin{tabular}{lll}
\hline Alloy Variant & Solution Treatment & Cooling medium \\
\hline U720Li & $4 \mathrm{hr} @ 1105^{\circ} \mathrm{C}$ & oil quench \\
U720LG & $4 \mathrm{hr} @ 1135^{\circ} \mathrm{C}$ & oil quench \\
U720LP & $4 \mathrm{hr} @ 1105^{\circ} \mathrm{C}$ & insulated air cool \\
\hline
\end{tabular}

Table I. Heat treatment conditions of alloy variants. All alloys received a subsequent two stage ageing treatment of $24 \mathrm{hr} @$ $650^{\circ} \mathrm{C}$ (air cool) followed by $16 \mathrm{hr} @ 760^{\circ} \mathrm{C}$ (air cool)

The materials were characterised by etching with Fry's reagent and subsequently image analysed to determine the grain size, incoherent (grain boundary) $\gamma^{\prime}$ size and volume fraction. Coherent $\gamma^{\prime}$ characterisation was performed using TEM carbon extraction replicas of each material so that size and size range distributions of the secondary and tertiary $\gamma^{\prime}$ could be found. Vickers hardness tests were also performed on cach of the materials so that the effect of heat treatment could be assessed in terms of mechanical strength (flow stress variations).

High temperature fatigue testing was conducted in both air and vacuum between $650^{\circ} \mathrm{C}$ and $725^{\circ} \mathrm{C}$ at an $\mathrm{R}$ ratio $=0.1$ using a trapezoidal 1-X-1-1 waveform where $X$ was the dwell time at maximum load of either 1 or 20 seconds. All vacuum testing was conducted on an Instron 8501 servohydraulic testing machine fitted with an ESH vacuum furnace attachment using single edged notch bend (SENB) specimens. Air environment testing was conducted at DERA Farnborough using compact tension (CT) specimens. Standard d-c potential drop techniques were used to monitor crack growth over the $\Delta K$ range $15-40 \mathrm{MPa} / \mathrm{m}$. Constant $\Delta \mathrm{K}$ tests were also conducted at a $\Delta \mathrm{K}$ of $20( \pm 2) \mathrm{MPa} \sqrt{\mathrm{m}}$ with cracks grown for approximately $2 \mathrm{~mm}$ under test conditions. Fracture surface and etched fracture surface sections were observed under the SEM to detcrmine the crack propagation mode.

\section{Results and discussion}

\section{Microstructural characterisation}

The composition of the U720Li was analysed by wet chemical analysis and is given in Table II

\begin{tabular}{lllll}
\hline $\mathrm{Cr}(w t \%)$ & $\mathrm{Co}(\mathrm{wt} \%)$ & $\mathrm{Ti}(\mathrm{wt} \%)$ & $\mathrm{Mo}(\mathrm{wt} \%)$ & $\mathrm{Al}(\mathrm{wt} \%)$ \\
\hline 15.92 & 14.57 & 5.18 & 2.98 & 2.44 \\
\hline $\mathrm{W}(\mathrm{wt} \%)$ & $\mathrm{Fe}(\mathrm{wt} \%)$ & $\mathrm{Zr}(\mathrm{wt} \%)$ & $\mathrm{B}(\mathrm{wt} \%)$ & $\mathrm{C}(\mathrm{wt} \%)$ \\
\hline 1.35 & 0.08 & 0.042 & 0.016 & 0.023 \\
\hline
\end{tabular}

Table II Chemical composition (wt\%) of U720Li, bal. Ni 
The microstructural characteristics and Vickers hardness of the alloy variants used in this study are presented in Table III.

\begin{tabular}{|c|c|c|c|c|c|}
\hline $\begin{array}{l}\text { Alloy } \\
\text { Variant }\end{array}$ & $\begin{array}{l}\text { Grain } \\
\text { Size } \\
(\mu \mathrm{m}) \\
\pm \text { S.D. }\end{array}$ & $\begin{array}{l}\text { Primary } \\
\gamma^{\prime} \quad(\mu \mathrm{m}) \\
\pm \text { S.D. } \\
{\left[\mathrm{V}_{\mathrm{f}}(\%)\right]}\end{array}$ & $\begin{array}{l}\text { Secon } \\
\text {-dary } \\
\gamma^{\prime}(\mathrm{nm}) \\
\pm \text { S.D. }\end{array}$ & $\begin{array}{l}\text { Tertiary } \\
\gamma^{\prime} \quad(\mathrm{nm}) \\
\pm \text { S.D. }\end{array}$ & $\begin{array}{l}\text { Vickers } \\
\text { Hardness } \\
\pm \text { S.D. }\end{array}$ \\
\hline U720Li & $\begin{array}{l}5.9 \\
\pm 2.5\end{array}$ & $\begin{array}{l}2.6 \pm 1.0 \\
{[18.2 \%]}\end{array}$ & $\begin{array}{l}102 \pm \\
51\end{array}$ & $16 \pm 22$ & $459 \pm 2.9$ \\
\hline $\begin{array}{l}\text { U720Li } \\
\text { (LG) }\end{array}$ & $\begin{array}{l}17.4 \\
\pm 8.3\end{array}$ & $\begin{array}{l}2.9 \pm 1.2 \\
{[6.9 \%]}\end{array}$ & $\begin{array}{l}190 \pm \\
110\end{array}$ & $17 \pm 17$ & $445 \pm 2.7$ \\
\hline $\begin{array}{l}\text { U720Li } \\
\text { (LP) }\end{array}$ & $\begin{array}{l}10.1 \\
\pm 3.4\end{array}$ & $\begin{array}{l}2.9 \pm 1.0 \\
{[23.2 \%]}\end{array}$ & $\begin{array}{l}254 \pm \\
135\end{array}$ & $27 \pm 25$ & $425 \pm 2.3$ \\
\hline
\end{tabular}

Table III. Microstructural characteristics of the alloy variants

From Table III it is apparent that the variation in solutionising temperature and cooling rates of $U 720 \mathrm{Li}$ have produced significant variations in grain size and coherent $\gamma^{\prime}$ sizes. The large grain variant (higher solutionising temperature) has a grain size three times that of the as-received alloy whilst coherent $\gamma^{\prime}$ sizes have increased somewhat. The volume fraction of grain boundary pinning primary $\gamma^{\prime}$ has decreased from $18.2 \%$ to $6.9 \%$. For all three variants the primary $\gamma^{\prime}$ size has remained similar. The range in grain size (reflected in the standard deviation) is greater for the larger grain size. The slower cooling rate has produced coherent secondary precipitates that are over twice the size of the as-received alloy. However, some grain growth has occurred as well as a somewhat counter-intuitive increase in the volume fraction of primary $\gamma^{\prime}$. All microstructural variants were produced from the same turbine disc material, and specimens were cut tangential to the disc rim, the variations achieved in grain size and primary $\gamma^{\prime}$ distribution may therefore also reflect microstructural variations within the disc (possibly due to differing heat schedules experienced in different sections of the disc.) Hardness testing indicates that increasing $\gamma^{\prime}$ size decreases flow stress, whilst increasing grain size has little effect (with similar implications for yield strength variations). This trend has been reported elsewhere (6) for more extreme variations in grain size and coherent $\gamma^{\prime}$ size in the same alloy.

\section{Fatigue testing of as-received $\mathrm{U} 720 \mathrm{Li}$ in air and vacuum}

The fatigue crack propagation (f.c.p.) rates obtained in air and vacuum for the as-received $\mathrm{U} 720 \mathrm{Li}$ are shown in Figure 1. Testing temperatures of 650 and $725^{\circ} \mathrm{C}$ with 1 second and 20 second dwells have been investigated. Very similar f.c.p. rates and $\mathrm{m}$-values have previously been reported with no effect of dwell in vacuum at $600^{\circ} \mathrm{C}$ and $650^{\circ} \mathrm{C}$ (6). In air crack growth rates at $650^{\circ} \mathrm{C}$ are considerably higher, but also show no apparent dwell effect. SEM examination of the fracture surfaces and etched fracture surface sections obtained from growth out and constant $\Delta \mathrm{K}$ tests (Figure $2 \mathrm{a}-\mathrm{b}$ ) obtained under vacuum at these temperatures showed flat, featureless cracking that was highly transgranular in nature. The similarity of the f.c.p. rates at $600^{\circ} \mathrm{C}$ and $650^{\circ} \mathrm{C}$ and the smooth, transgranular crack growth mode indicate that crack growth under these conditions may be of a purely cyclic nature. Tests in air at $650^{\circ} \mathrm{C}$ revealed a mixed (transgranular and intergranular) crack growth mode both with and without dwell (Fig 2c)

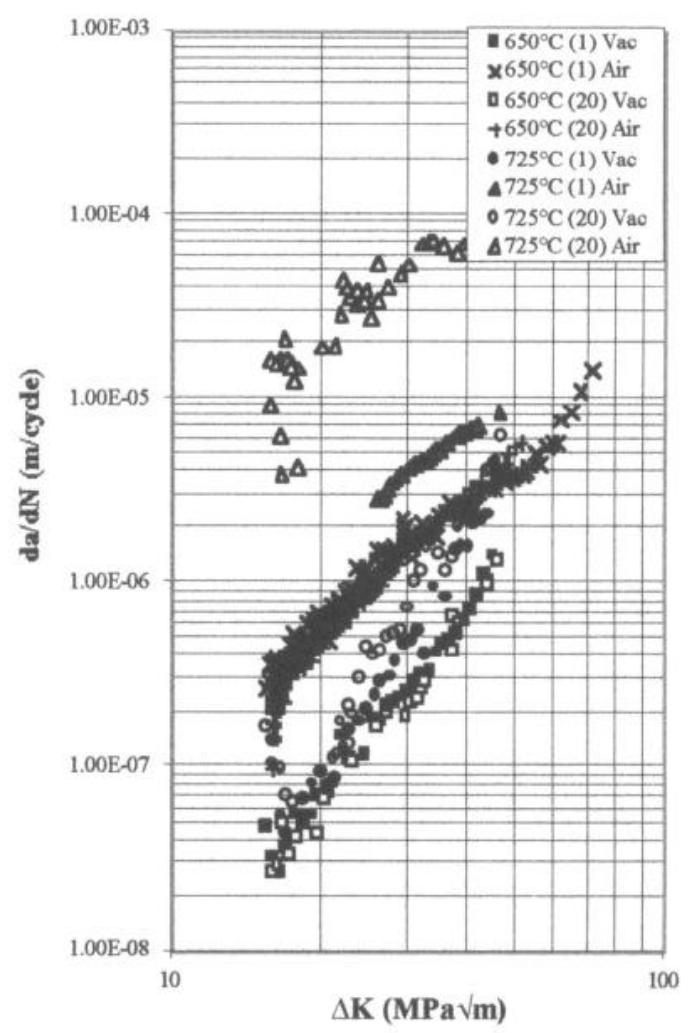

Figure 1 Comparison of behaviour in air and vacuum in U720Li (as-received)

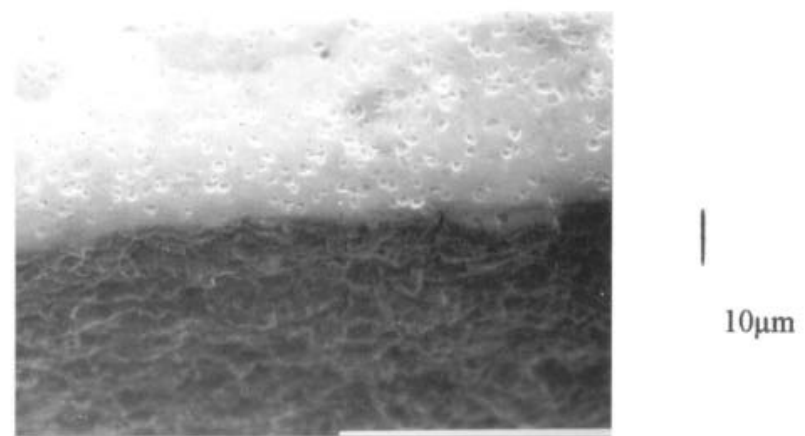

Fig 2a Fracture surface section showing transgranular crack path obtained under1-1-1-1 loading at $650^{\circ} \mathrm{C}$ in U720 Li

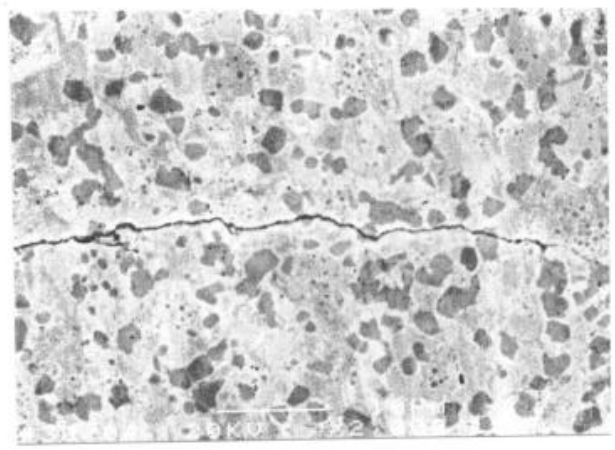

$10 \mu \mathrm{m}$

Fig $2 \mathrm{~b}$ Sectioned constant $\Delta \mathrm{K}$ test; U720Li, $650^{\circ} \mathrm{C}$ (1-1-1-1), $\Delta \mathrm{K}=20 \mathrm{MPa} \sqrt{\mathrm{m}}$, crack tip region 

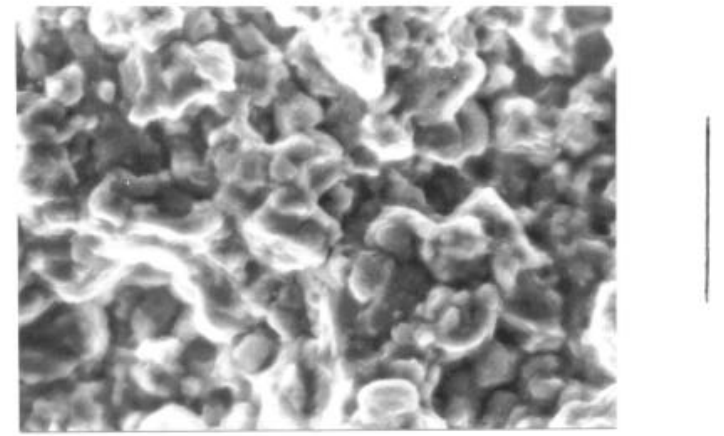

$10 \mu \mathrm{m}$

Fig 2c Fracture surface in air; U720Li, $650^{\circ} \mathrm{C}$ (1-1-1-1)

The f.c.p. rates and m-values for U720 Li in vacuum are seen to increase as test temperature and dwell time at maximum load are increased. SEM observations of tests conducted at $725^{\circ} \mathrm{C}$ in vacuum indicated much rougher fracture surfaces (c.f. lower temperature tests) with the failure modes becoming increasingly intergranular in nature as dwell times were increased (Figure 3a).
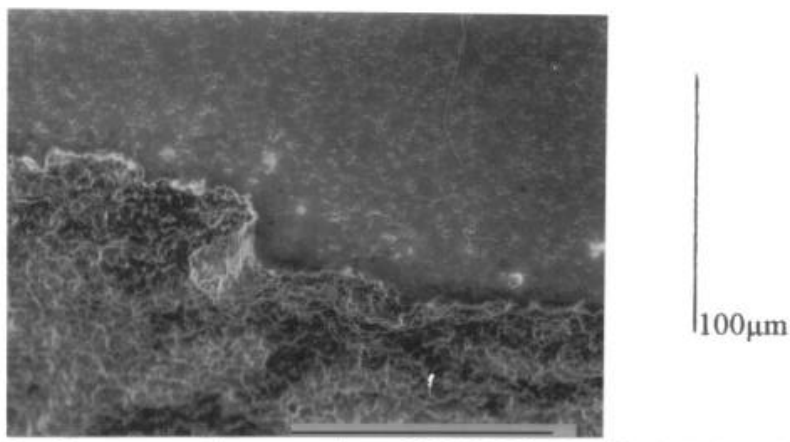

Fig 3a Fracture surface section of U720Li $725^{\circ} \mathrm{C}$ (1-20-1-1) showing typical intergranular cracking

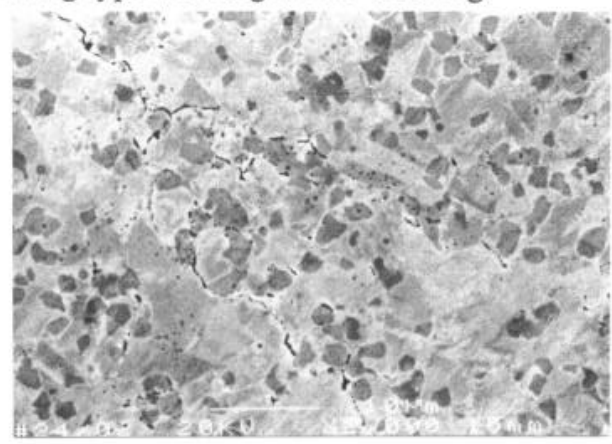

Fig 3b Sectioned constant $\Delta \mathrm{K}$ test; U720Li, $725^{\circ} \mathrm{C}$ (1-20-1-1), $\Delta \mathrm{K}=20 \mathrm{MPa} \sqrt{\mathrm{m}}$, crack tip region

Crack tunnelling was also evident for tests conducted under these conditions. The change in crack growth mode coupled with the increasing f.c.p. rates and m-values noted may indicate the presence of time dependent (creep-fatigue) behaviour. Analysis of constant $\Delta \mathrm{K}$ tests using backscattered SEM showed that at $725^{\circ} \mathrm{C}$ voids were appearing ahead of the crack tip (Figure $3 \mathrm{~b}$ ) and were seen to be more prevalent as dwell time was increased. This further indicates the presence of static creep modes under these conditions.

The effect of environment can also be seen in Figure 1 where the vacuum data is compared with CT tests carried out in air at
DERA Farnborough. In an air environment, crack growth rates are much higher under all testing conditions with increases noted as temperature and dwell times are increased. Of significance are the slopes of the crack growth curves (mvalues), which remain relatively constant over all the testing conditions. Intergranular cracking modes were also noted to predominate under all testing temperatures and dwell times, indicating that the mechanism of crack growth remains constant throughout. This is in contrast to the vacuum data where m-values increased and the crack growth mode changed from transgranular to intergranular as test temperatures and dwell times were increased. In an air environment the results indicate that oxidation embrittlement along grain boundaries dominates the nature of crack growth under all testing conditions. This would explain the constant m-values and the consistently mixed or intergranular nature of the crack growth observed. However, in vacuum the effects of oxidation are effectively removed and at high temperatures with lower frequencies (increased dwell), the change in m-values and crack growth mode would indicate the onset of true creep processes. It is unlikely that any true creep processes can occur in an air environment as the oxidation assisted crack growth occurs at such a rate that there is insufficient time for creep processes to occur, in addition they would be insignificant with respect to the effect of oxidation.

Fatigue testing of the large grain and precipitate microstructural variants in air and vacuum

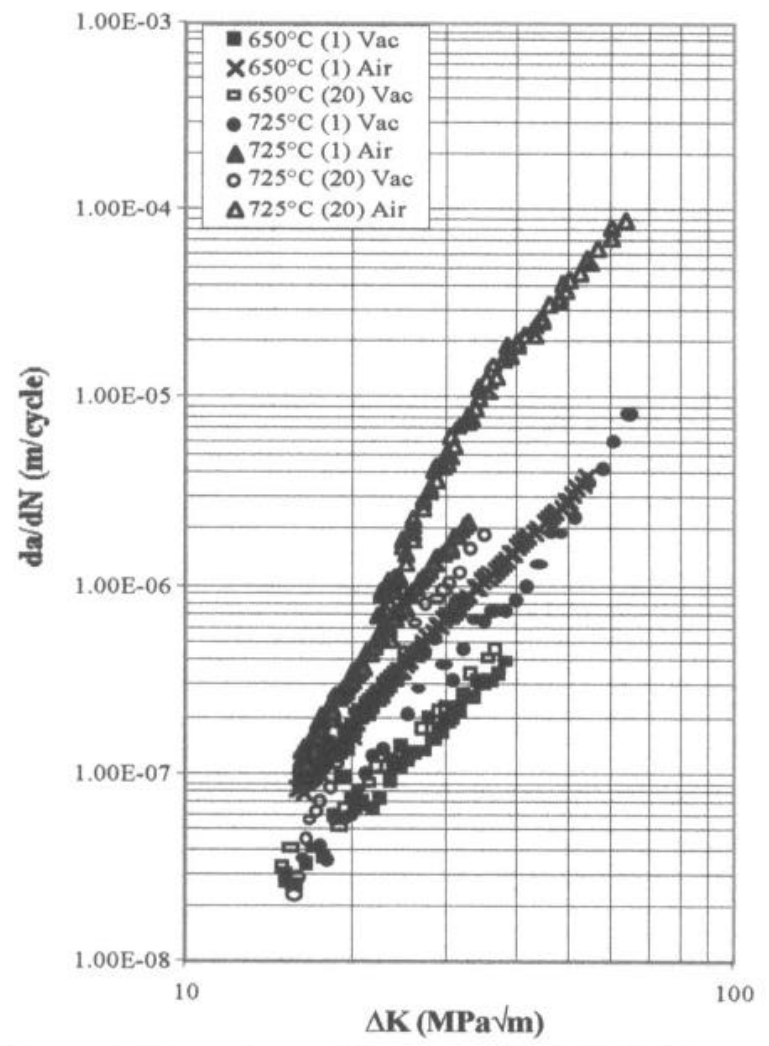

Figure 4: Comparison of f.c.p. rates in U720LG in air and vacuum 


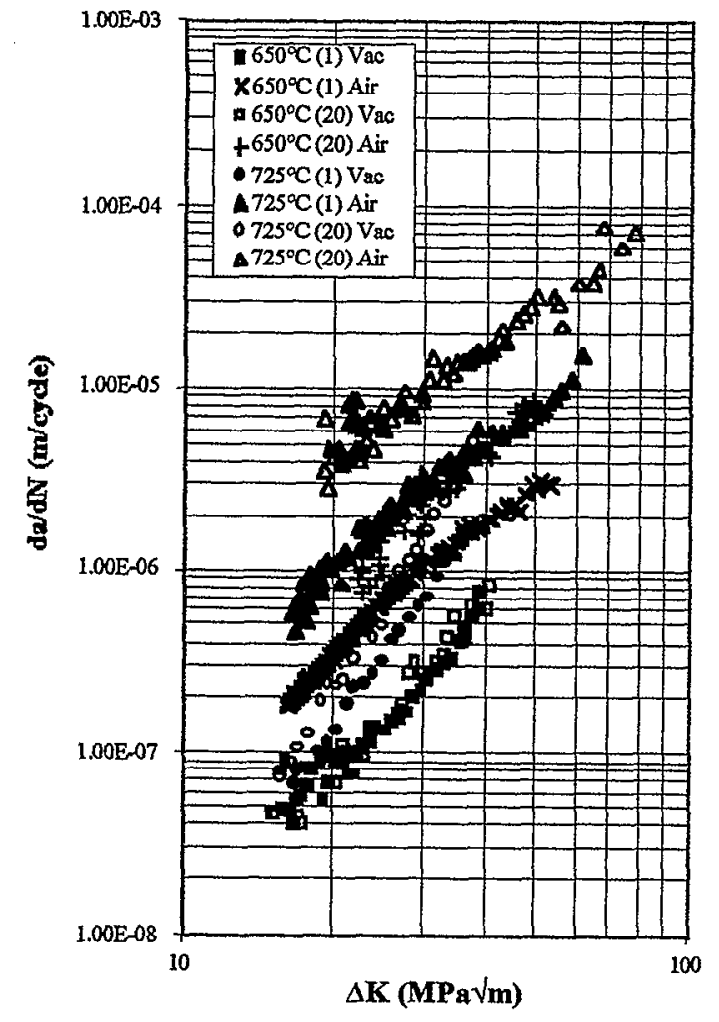

Figure 5: Comparison of f.c.p. rates in U720LP in air and vacuum

Similar trends are seen in both the U720LG and LP microstructural variants in air and vacuum at $650^{\circ} \mathrm{C}$ and $725^{\circ} \mathrm{C}$. Lower crack growth rates are seen in vacuum than in air, with no dwell effect observed at $650^{\circ} \mathrm{C}$ in vacuum. The U720Li variants with fine $\gamma^{\prime}$ precipitates (U720Li and U720LG) show no effect of dwell in air at $650^{\circ} \mathrm{C}$, whereas the coarser $\gamma^{\prime}$ variant (U720LP) shows an approximate twofold increase in $\mathrm{da} / \mathrm{dN}$ as the dwell increases from 1s to $20 \mathrm{~s}$. Increasing temperature leads to increased crack growth rates for all conditions in both air and vacuum and increased dwell at $725^{\circ} \mathrm{C}$ also leads to increased crack growth rates in both air and vacuum. Transgranular crack growth modes were observed at $650^{\circ} \mathrm{C}$ in vacuum for all microstructural variants, whilst at the higher temperatures and dwells increasing proportions of intergranular failure were observed in vacuum. In air mixed or intergranular crack growth modes were observed.

Comparison of the effect of grain size and $\gamma^{\prime}$ vrecinitate size on high temperature fatigue in U720Li

The microstructural analysis work indicates that increasing grain size appears to have less of an effect on flow stress than increasing $\gamma^{\prime}$ precipitate size. In Figures 6-9 a comparison of the effect of an increase in grain size (from $5.9 \mu \mathrm{m}$ to $17 \mu \mathrm{m}$ ) on the high temperature fatigue behaviour of U720Li in air and vacuum can be seen. At $650^{\circ} \mathrm{C}$ there appears to be only a very slight advantage (if any at all) observed in terms of f.c.p. resistance of the large grain size variant over the base-line material in vacuum (with or without dwell), whereas in air the benefits of increased grain size at $650^{\circ} \mathrm{C}$ are far more evident and more marked for the longer dwell. The slight expected reduction in flow strength at $650^{\circ} \mathrm{C}$ for the larger grain size

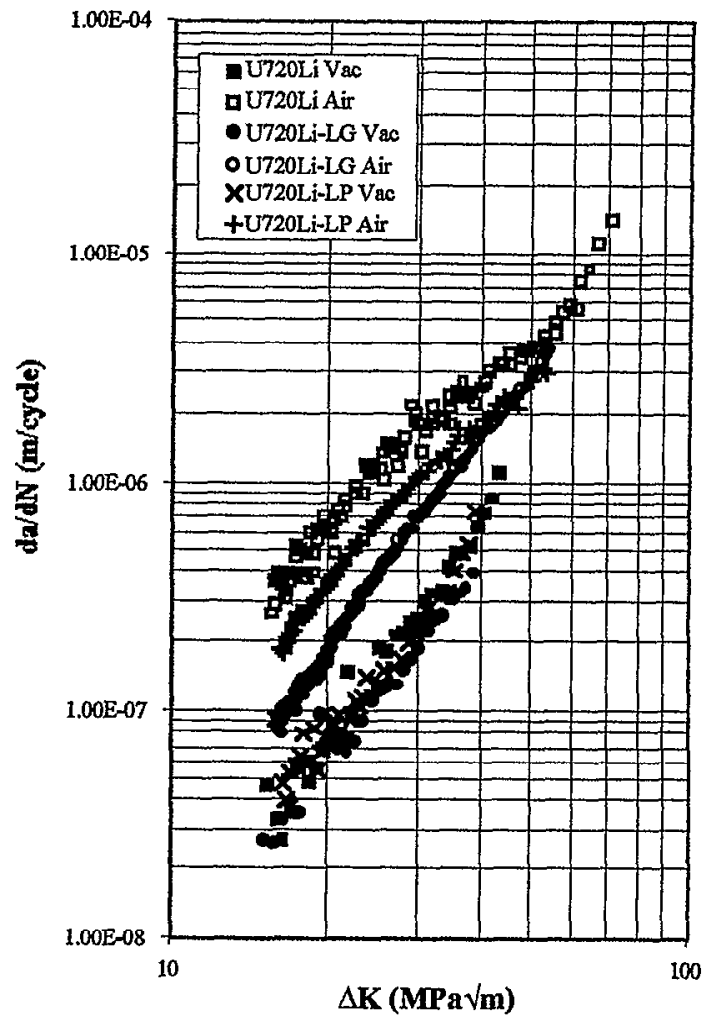

Figure 6: Comparison of f.c.p. rates 1-1-1-1 cycle at $650^{\circ} \mathrm{C}$ in U720Li, U720LG and U720LP in air and vacuum.

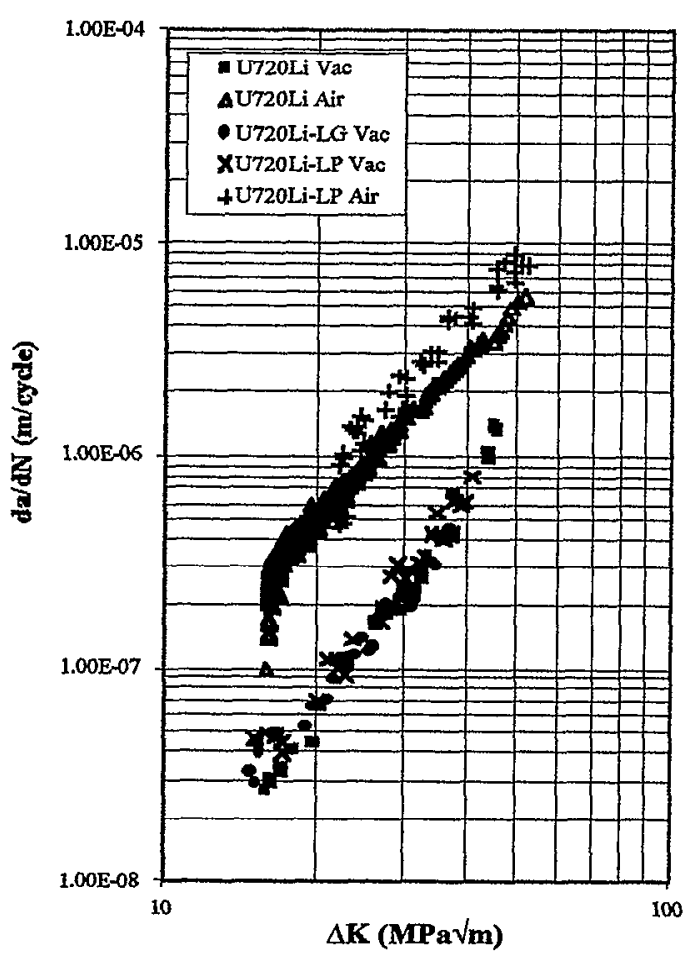

Figure 7: Comparison of f.c.p. ratcs $1-20-1-1$ cycle at $650^{\circ} \mathrm{C}$ in $\mathrm{U} 720 \mathrm{Li}, \mathrm{U} 720 \mathrm{LG}$ and U720LP in air and vacuum 
does not seem to have reduced the crack propagation resistance. In the purely cyclic dependent regime $\left(650^{\circ} \mathrm{C}\right.$ in vacuum) there appears to be little effect of increased grain size, indicating that the reduced damage accumulation expected for larger grain sizes has not contributed to improving fatigue crack growth resistance. In air, where a mixed transgranular/intergranular crack growth mechanism predominates and oxidation cmbrittlcment of the grain boundaries accelerates crack growth rates, the benefit of the larger grain size is much more pronounced. This can be linked to the reduced amount of grain boundary area for the larger grain size, limiting the extent of the oxidation embrittlement. In addition the larger grain sized material will have more tortuous and deflected crack growth, yielding an increased shielding effect, and hence a lowered $\Delta K$ will be experienced at the crack tip compared with the finer grain sized variants which will have a less tortuous crack path profile. The U720LP variant has a slightly coarser grain size $(10.1 \mu \mathrm{m}$ c.f $5.9 \mu \mathrm{m})$ and this yields slightly improved f.c.p. resistance at $650^{\circ} \mathrm{C}$ in air with a one second dwell, but at a longer dwell (more oxidation embrittlement, Figure 7) the f.c.p. resistance is lowered. Previous studies $(9,10)$ have reported an improvement in oxidation fatigue resistance with an increase in coherent $\gamma^{\prime}$ size, but this is not supported by our findings. At $725^{\circ} \mathrm{C}$ the effect of grain size is quite marked in air both with and without dwell (Figures 8 and 9), with the slowest crack growth again observed for the larger grain sized material. The vacuum data however shows only a very slight improvement in f.c.p. resistance even in the creep-fatigue regime $\left(725^{\circ} \mathrm{C}, 20\right.$ second dwell). The large precipitate variant showed similar or slightly worse f.c.p. resistance than the baseline, as-received $\mathrm{U} 720 \mathrm{Li}$ at $725^{\circ} \mathrm{C}$ in vacuum with and without dwell and in air without dwell. In air at $725^{\circ} \mathrm{C}$ with dwell, the U720LP shows improved f.c.p. resistance over the as-received U720Li (although the U720LG still shows the best fatigue resistance). The flow stress of the U720LP material is likely to be somewhat lower than that of the U720LG and U720Li variants, and this, together with the higher proportion of grain boundary $\gamma^{\prime}$ as well as the coarser coherent $\gamma^{\prime}$ should be taken into account in considering these results.

At $725^{\circ} \mathrm{C}$ in air with a 20 second dwell intergranular cracking modes appeared to predominate (indicating time-dependent oxidation behaviour) and it is this growth mode that is thought to favour the LP microstructure in terms of increasing resistance to crack growth. It should also be noted that the grain size and volume fraction of primary $\gamma^{\prime}$ had been increased somewhat over that of the base-line U720Li which may also contribute to increased creep-fatigue crack growth resistance as these features can help to restrict grain boundary sliding. It is therefore instructive to consider the nature of the grain boundary in more detail, particularly the nominal line fraction of primary grain boundary $\gamma^{\prime}$ along the grain boundaries.

Line-fraction estimation of grain boundary $\gamma^{\prime}$ along the grain boundaries

We have assumed a hexagonal-type array of equi-sized grains, with equivalent area and circularity to the average grain size determined by image analysis for each microstructural variant. The circularity is defined as:

$$
\text { circularity }=\frac{4 \pi \cdot \text { area }}{\text { perimeter }}
$$

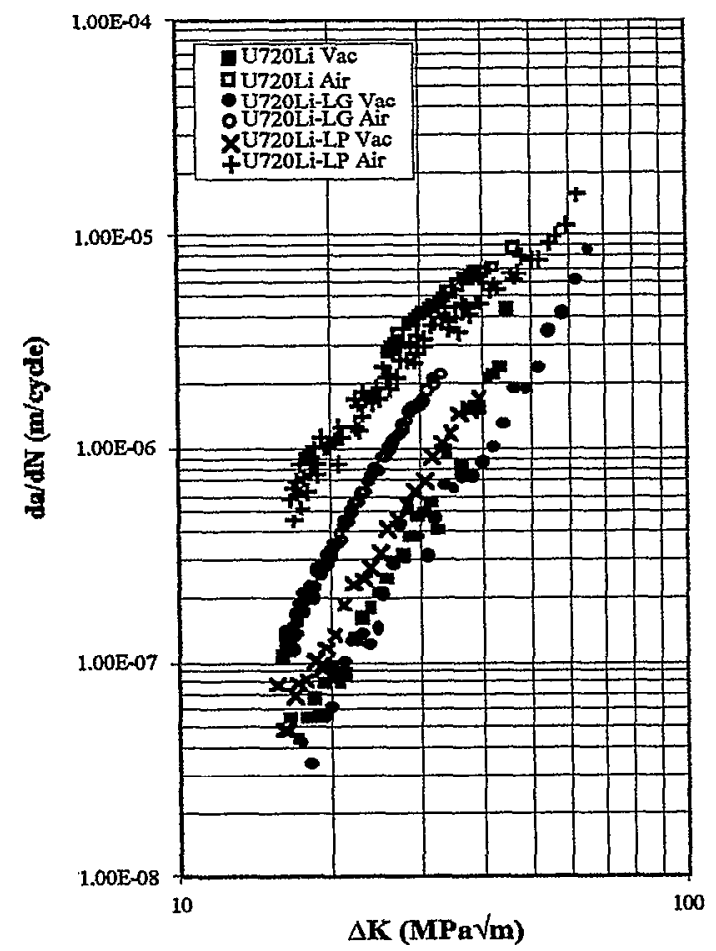

Figure 8: Comparison of f.c.p. rates 1-1-1-1 cycle at $725^{\circ} \mathrm{C}$ in U720Li, U720LG and U720LP in air and vacuum regime.

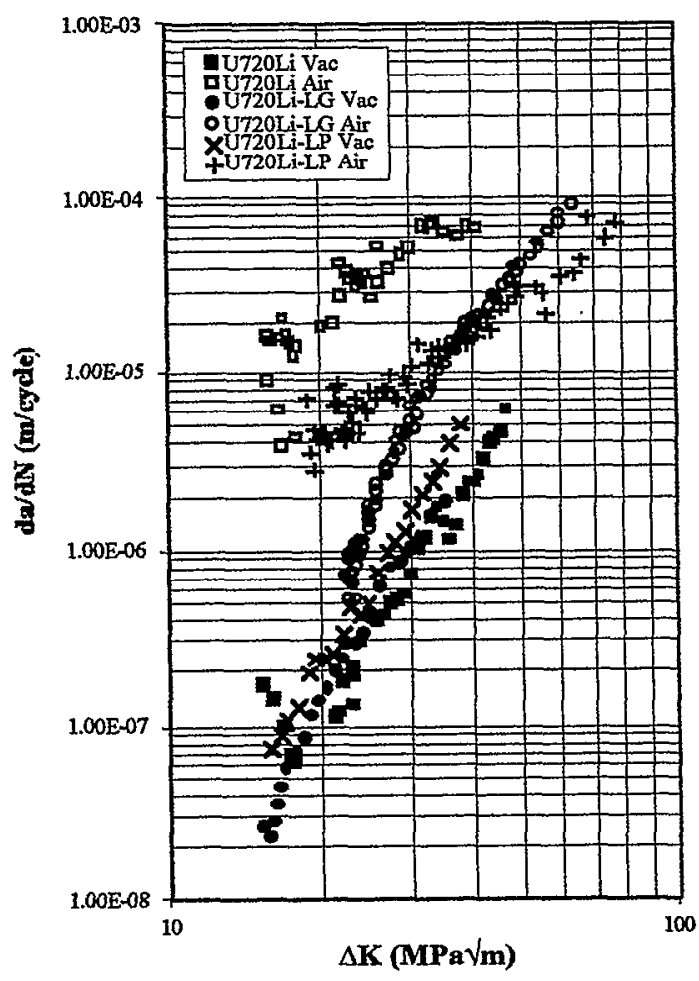

Figure 9: Comparison of f.c.p. rates 1-20-1-1 cycle at $725^{\circ} \mathrm{C}$ in U720Li, U720LG and U720LP in air and vacuum regime. 
Hence yielding a circularity of 1.0 for a circle, the average circularity for the three grain sizes was found to be 0.66 . The grain dimensions and the grain array considered in this estimation are shown in Figure 10

All internal angles are assumed to be $120^{\circ} \mathrm{C}$
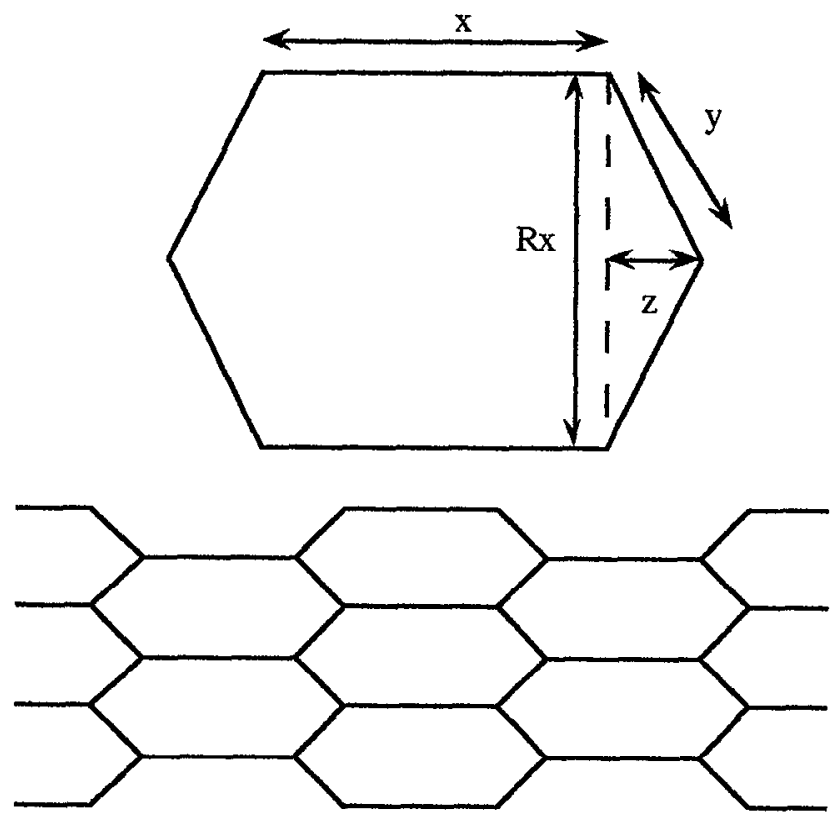

Figure 10 - Grain dimensions and grain array considered in line fraction estimation

An elongated hexagonal grain shape was chosen (as shown in Figure 10) $R$ was chosen to be 0.4 to yield a circularity of 0.66 . All internal angles have been taken as $120^{\circ}$, yielding the following relationships for the grain dimensions:

$$
\begin{aligned}
& y=\frac{R x}{2 \cos 30^{\circ}} \\
& z=\frac{R x \sin 30^{\circ}}{2 \cos 30^{\circ}}
\end{aligned}
$$

where $x$ is chosen to yield an equivalent area to the grain size area for each microstructural variant. The total grain boundary length within the grain array is then:

$$
\text { g.b.length }=24 y+18 x=\left(\frac{12 R}{\cos 30^{\circ}}+18\right) x
$$

whilst the area of the grain array is:

$$
\text { arrayarea }=12\left(R x^{2}+\frac{R^{2} x^{2} \sin 30^{\circ}}{2 \cos 30^{\circ}}\right)+3 R x^{2}
$$

The length of grain boundary per $\mathrm{m}^{2}$ is then simply eqn (4) divided by eqn (5). The number density of primary grain boundary $\gamma^{\prime}$ per $\mathrm{m}^{2}$ is estimated as the ratio of the $V_{\mathrm{f}} \gamma^{\prime}$ (equivalent to the area fraction) and the estimated average $\gamma^{\prime}$ area (making a simple circular assumption). Then, assuming the primary $\gamma^{\prime}$ always sits on a grain boundary the line fraction of primary $\gamma^{\prime}$ along the grain boundaries can be seen to be:

$$
\text { Linefraction }=\frac{\text { no.density } \times \gamma^{\prime} \text { diameter }}{\text { g.b.length } / \mathrm{m}^{2}}
$$

Table IV lists the various estimates for the three microstructural variants

\begin{tabular}{|l|l|l|l|l|l|l|}
\hline Alloy & $\begin{array}{l}\text { Grain } \\
\text { Area } \\
\left(\mathrm{m}^{2}\right)\end{array}$ & $\begin{array}{l}\mathrm{x} \\
(\mathrm{m})\end{array}$ & $\begin{array}{l}\text { array } \\
\text { g.b. } \\
\text { length } \\
(\mathrm{m})\end{array}$ & $\begin{array}{l}\text { array } \\
\text { area } \\
\left(\mathrm{m}^{2}\right)\end{array}$ & $\begin{array}{l}\text { No. } \\
\text { dens- } \\
\text { ity } \gamma^{\prime}\end{array}$ & $\begin{array}{l}\text { Line } \\
\text { Fract- } \\
\text { ion }\end{array}$ \\
\hline $\begin{array}{l}\mathrm{U} 720 \\
\mathrm{Li}\end{array}$ & $\begin{array}{l}2.734 \\
\times 10^{-11}\end{array}$ & $\begin{array}{l}7.82 \\
\mathrm{x} 0^{-6}\end{array}$ & $\begin{array}{l}1.841 \mathrm{x} \\
10^{-4}\end{array}$ & $\begin{array}{l}4.015 \\
\times 10^{-10}\end{array}$ & $\begin{array}{l}3.428 \\
\times 10^{10}\end{array}$ & 0.194 \\
\hline $\begin{array}{l}\mathrm{U} 720 \\
\mathrm{LP}\end{array}$ & $\begin{array}{l}8.012 \\
\times 10^{-11}\end{array}$ & $\begin{array}{l}13.4 \\
\times 10^{-6}\end{array}$ & $\begin{array}{l}3.155 \times \\
10^{-4}\end{array}$ & $\begin{array}{l}1.177 \\
\times 10^{-9}\end{array}$ & $\begin{array}{l}3.512 \\
\times 10^{10}\end{array}$ & 0.380 \\
\hline $\begin{array}{l}\mathrm{U} 720 \\
\mathrm{LG}\end{array}$ & $\begin{array}{l}2.378 \\
\mathrm{x} 10^{-10}\end{array}$ & $\begin{array}{l}23.1 \\
\mathrm{x} 10^{-6}\end{array}$ & $\begin{array}{l}5.438 \mathrm{x} \\
10^{-4}\end{array}$ & $\begin{array}{l}3.494 \\
\times 10^{-9}\end{array}$ & $\begin{array}{l}1.045 \\
\times 10^{10}\end{array}$ & 0.195 \\
\hline
\end{tabular}

Table IV - line fraction estimates

It seems that the lower area fraction of grain boundary $\gamma^{\prime}$ in the large grain sized variant compared with the as-received material can be directly related to the reduction in grain boundary area. A very similar line fraction of grain boundary $\gamma^{\prime}$ is estimated for both the as-received U720Li and the U720LG. The U720LP had an increased area fraction of grain boundary $\gamma^{\prime}$ compared with the as-received material, despite having a somewhat larger grain size, and this is reflected in the higher estimated line fraction of grain boundary $\gamma^{\prime}$ (almost twice as high). It is clear that the U720LP material has significantly more primary grain boundary $\gamma^{\prime}$ along the grain boundaries than the other two variants as well as coarser coherent $\gamma^{\prime}$. The nature of the grain boundary is clearly different for the U720LP and this may go someway towards explaining it's improved performance under the most severe conditions $\left(725^{\circ} \mathrm{C}\right.$ in air 1-20-1-1 cycle). Under these conditions the crack growth behaviour is dominated by the nature of the grain boundary since intergranular crack growth modes predominate. The increased amount of primary g.b. $\gamma^{\prime}$ is thought to reflect the fact that the original $U 720 \mathrm{Li}$ material, prior to the $\gamma^{\prime}$ coarsening heat treatment, may have experienced a slightly different solution treatment due to it's position within the turbine disc.

Attempting to systematically vary the powder metallurgy microstructure is a complex business. Altering grain size requires longer solutionising times and temperatures to remove some of the grain boundary pinning primary $\gamma^{\prime}$ which will then allow grain growth. Significant coarsening of grain size in this way is not easily controllable, and can lead to very anisotropic grain structures containing blown grains, when some grains grow extremely fast. Even when similar grain boundary character has been retained (as is the case for our

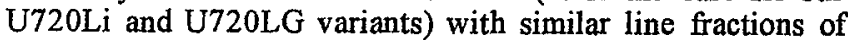
primary $\gamma^{\prime}$ along the grain boundaries, the amount of coherent 
$\gamma^{\prime}$ will have been altered. To illustrate this we have estimated the proportion of coherent $\gamma^{\prime}$ in each microstructure, based upon equilibrium predictions of the total amount of $\gamma^{\prime}$ and our experimental measurements of primary $\gamma^{\prime}$. The equilibrium predictions have been made at Cambridge University using Thermo-calc, a commercially available thermodynamic prediction programme, using a proprietary Rolls Royce thermodynamic databasc.

\begin{tabular}{|l|lr|l|l|}
\hline Material & $\begin{array}{l}\text { Total } \\
\text { predicted } \\
250{ }^{\circ} \mathrm{C}\end{array}$ & $\begin{array}{l}\gamma^{\prime} \\
\text { at }\end{array}$ & $\begin{array}{l}\text { Primary } \gamma^{\prime} \\
\text { from } \\
\text { micrographs }\end{array}$ & $\begin{array}{l}\text { Remaining } \\
\text { (predicted) } \\
\text { coherent } \gamma^{\prime}\end{array}$ \\
\hline U720Li & $48.3 \%$ & $18.2 \%$ & $30.1 \%$ \\
\hline U720LP & $48.3 \%$ & $23.2 \%$ & $25.1 \%$ \\
\hline U720LG & $48.3 \%$ & $6.9 \%$ & $41.4 \%$ \\
\hline
\end{tabular}

Table V - Predicted amounts of coherent $\gamma^{\prime}$ in each variant

It can be seen that the large grain sized variant (U720LG) is predicted to have the highest proportion of coherent $\gamma^{\prime}$ whilst the U720LP has the lowest. Thus changing grain size also affects the proportions of coherent and incoherent (primary) $\gamma^{\prime}$. In the case of the U720LP, the $\gamma^{\prime}$ coarsening heat treatment has resulted in an unexpected variation in grain size and proportion of primary $\gamma^{\prime}$ (which may reflect solution heat treatment variations within the disc). Hence it is hard to unambiguously resolve the relative contributions of grain size, grain boundary character (e.g. line-fraction of grain boundary primary $\gamma^{\prime}$ ) coherent $\gamma^{\prime}$ size and proportion in the high temperature fatigue and oxidation/creep fatigue behaviour. In addition, the effect of these microstructural variables on flow stress may affect the crack tip strain range experienced at cquivalent applied stresses.

Normalising for these effects will allow the effect of micromechanism changes due to microstructure variation to be more clearly established. Assuming the ratio of room temperature hardness values gives a rcasonable estimate of the ratio of difference in yield strength at the test temperatures of interest, no change in $\mathrm{E}$, and:

$$
\triangle C T O D=\frac{\Delta K^{2}}{\sigma_{y} E}
$$

then taking the hardness of $U 720 \mathrm{Li}$ as the baseline, $\sim 1.5 \%$ increase in "effective" $\Delta \mathrm{K}$ experienced at the crack can be estimated for the U720LG case, and $4 \%$ increase in "effective" $\triangle K$ experienced at the crack can be estimated for the U720LP case. Such changes will increase the normalised $\Delta \mathrm{K}$ levels by negligible amounts in the log-log plots. Clearly the true high temperature flow stress behaviour should be ascertained for each microstructural condition to establish whether the microstructural changes have affected global mechanical properties.

This work indicates that a larger grain size material has the best high temperature fatigue, creep fatigue and oxidation fatigue resistance, but it should be noted that there are inherent problems with reproducibility of a consistent microstructure when attempting to produce a significant increase in grain size in this class of materials.
Summary and conclusions

The time-dependent crack growth regime in air is primarily due to oxidation assisted crack growth, since any underlying "true" creep-fatigue behaviour, such as that witnessed at $725^{\circ} \mathrm{C}$ in vacuum is swamped by rapid oxidation effects.

The effect of varying grain size (whilst maintaining similar $\gamma^{\prime}$ sizes) on f.c.p. rates in vacuum has been evaluated. A larger grain size offers little benefit in resisting creep-fatigue and cycle-dependent fatigue. This indicates that there is little reduced intrinsic driving force for fatigue crack growth for an increased grain size. Our results do not support the argument for less damage accumulation $(14,15)$ due to increased slip reversibility to higher crack tip stress levels as crack tip plasticity is contained within a larger grain. The beneficial effect of larger grain size expected in the "true" creep-fatigue regime in vacuum, where the decreased number of grain boundaries might be expected to offer more resistance to intergranular grain boundary creep failure mechanisms, has not been shown. The larger grain sized material does however show improved oxidation fatigue resistance over all temperatures in air, where an intergranular oxidation embrittlement process occurs. Altering grain size was found to have little effect on the room temperature hardness of the material, whereas altering the coherent $\gamma^{\prime}$ size gave far greater effects. Normalising for the expected variation in yield strength at test temperature indicated a negligible effect of this mechanical property variation on high temperature fatigue resistance.

In terms off.c.p. behaviour, larger coherent precipitates do not offer improved performance when static creep failure modes appear to dominate in vacuum or under pure cyclic fatigne conditions in vacuum. In air the U720LP material showed slightly improved f.c.g. resistance at $650^{\circ} \mathrm{C}$ with a 1-1-1-1 cycle, although this effect disappeared with the introduction of a dwell and was not evident for the $725^{\circ} \mathrm{C} 1-1-1-1$ cycle. Under the most severe conditions $\left(725^{\circ} \mathrm{C} 1-20-1-1\right.$ in air) the U720LP variant showed improved f.c.g. resistance c.f the baseline material (although the large grain sized variant still offered the best performance). The slightly larger grain size and volume fraction of primary $\gamma^{\prime}$ may also be a factor within this regime where intergranular failure modes are important.

\section{Further Work}

Further work is planned to establish the tensile behaviour of all microstructural variants at the test temperatures of interest. The line fraction estimates of grain boundary $\gamma^{\prime}$ will be confirmed by experimental measurements using image analysis. Representative measures of crack deflection will be taken and the effect of crack path in producing extrinsic shielding effects assessed. This will allow the assessment of micromechanistic contributions aside from extrinsic shielding effects or reduced $\triangle C T O D$ due to yield stress variations. All the work described here relates to long crack propagation, and a further programme of work is planned to assess the high temperature fatigue performance of the microstructural variants in terms of crack initiation and short crack growth which may have more relevance to the turbine disc service application. 


\section{Acknowledgements}

The work in this paper has been supported by the Mechanical Sciences Sector, DERA Farnborough under DTI-CARAD MOD Applied Research Package funding whose support is gratefully acknowledged. Rolls Royce plc are thanked for the supply of materials, use of equipment and technical discussion. The assistance of T.Powell and A.Tucker in carrying out the air testing at DERA Farnborough is gratefully acknowledged. $D$. Hunt is also thanked for doing the Thermo-calc predictions at the University of Cambridge.

C British Crown Copyright 2000.

Published with the permission of the Controller of Her Britannic Majesty's Stationary Office.

\section{References}

1. J.E. King, "Fatigue crack propagation in nickel-base superalloys-effects of microstructure, load ratio, and temperature", Mat. Sci. Tech. 3, (1987), 750-764.

2. H.H. Smith and D.J. Michel, "Effect of environment on fatigue crack propagation behaviour of alloy 718 at elevated temperatures", Met Trans. A 17A, (1986), 370-374.

3. R.P. Skelton (ed.), Eatigue at high temperature, (Elsevier Applied Science, Oxford, 1983), 224.

4. L. Davis (ed.), ASM speciality handbook: Heat resistant materials, (ISBN 0871705966, ASM, 1997), 500.

5. E. Andrieu, R. Molins, H. Ghonem and A. Pineau, "Intergranular crack tip oxidation mechanism in a nickelbased superalloy", Mat. Sci. Eng, A154 (1992), 21-28.

6. N.J. Hide, M.B. Henderson, A. Tucker and P.A.S. Reed, "The effects of microstructure and environment on high temperature fatigue and creep-fatigue mechanisms in a nickel base superalloy" Progress in mechanical behaviour of materials ed. F. Ellyin and J.W. Provan (ICM8, Victoria, Canada, 1999), I, 429-434

7. L. Garimella, P.K. Liaw and D.L. Klarstrom, "Fatigue behaviour in nickel-based superalloys: A literature review", Journal of Metals 49(7), (1997), 67-71.

8. T. Isomoto and N.S. Stoloff, "Effect of microstructure and temperature on high cycle fatigue of powder metallurgy Astroloy", Mat. Sci. Eng, A124, (1990), 171-181.

9. H.F. Merrick and S. Floreen, "The effects of microstructure on elevated temperature crack growth in nickel-based alloys", Met Trans. A 9A, (1978), 231-236.

10. H. Ghonem, T. Nicholas and A. Pineau, "Elevated temperature fatigue crack growth in alloy 718-part II: Effects of environmental and material variables", Fat \& Fract Engng Mat.\& Struct. 16 (6) (1993), 577-590.
11. E. Andrieu, G. Hochstetter, R. Molins and A. Pineau, "Oxidation mcchanisms in relation to high temperature fatigue crack growth properties of alloy 718", Superallovs 718.625 . 706 and Various Derivatives (ed. E.A. Loria), (The Minerals, Metals and materials society, 1994), 619-631.

12. F. Torster, G. Baumeister, J. Albrecht, G. Lütjering, D. Helm and M.A. Daeubler, "Influence of grain size and heat treatment on the microstructure and mechanical properties of the nickel-base superalloy U720Li", Mat. Sci. Eng A A234236, (1997), 189-192.

13. J.C. Runkel and R.M. Pelloux "Micromechanisms of lowcycle fatigue in nickel based superalloys at elevated temperatures" In Fatigue Mechanism (ed. J.T. Fong), ASTM STP $675,(1979) 501-527$

14. A. Lasalmonie and J.L. Strudel, "Influence of grain size on the mechanical behaviour of some high strength materials" $\mathrm{J}$ Mat Sci. 21, (1986) 1837-1852

15. D.D. Krueger, S.D. Antolovich and R.H. Van Stone, "Influence of grain size and precipitate size on the fatigue crack growth behaviour of alloy 718 at $427^{\circ} \mathrm{C}$ "Met. Trans. A $18 A$ (1987) 1431-1448 